\title{
The influence of circulating fibrinogen level on postoperative blood loss and blood transfusion in pediatric cardiac surgery: a retrospective observational study
}

\author{
Gyeong-Jo Byeon ${ }^{1,2}$, Ji-Uk Yoon ${ }^{1,2}$, Hye-Jin Kim ${ }^{1}$, Eun-Ji Choi ${ }^{3}$, Eun-Jung Kim ${ }^{3,4}$, Seyeon Park ${ }^{1}$, \\ Soon Ji Park ${ }^{1}$, Wonjae Heo ${ }^{1}$, Hee Young Kim ${ }^{1 \wedge}$ \\ ${ }^{1}$ Department of Anesthesia and Pain Medicine, Pusan National University Yangsan Hospital, Yangsan, Korea; ${ }^{2}$ Department of Anesthesia and Pain \\ Medicine, School of Medicine, Pusan National University, Yangsan, Korea; ${ }^{3}$ Department of Dental Anesthesia and Pain Medicine, Pusan National \\ University Dental Hospital, Yangsan, Korea; ${ }^{4}$ Department of Dental Anesthesia and Pain Medicine, School of Dentistry, Pusan National University, \\ Dental Research Institute, Yangsan, Korea \\ Contributions: (I) Conception and design: GJ Byeon, HY Kim; (II) Administrative support: HY Kim; (III) Provision of study materials or patients: HY \\ Kim; (IV) Collection and assembly of data: HY Kim; (V) Data analysis and interpretation: GJ Byeon, HY Kim; (VI) Manuscript writing: All authors; \\ (VII) Final approve of manuscript: All authors. \\ Correspondence to: Hee Young Kim, MD, PhD. Department of Anesthesia and Pain Medicine, Pusan National University, Yangsan Hospital, 20, \\ Geumo-ro, Beomeo-ri, Mulgeumeup, 50612, Yangsan, Korea. Email: anekhy@gmail.com.
}

Background: Pediatric patients are at high risk of massive bleeding after cardiac surgery under cardiopulmonary bypass (CPB). Fibrinogen is essential for coagulation; however, pediatric patients with congenital heart disease (CHD) present abnormal fibrinogen function. The pre- and post-operative fibrinogen level may affect the bleeding and transfusion amount in patients undergoing cardiac surgery. However, the relationship between plasma fibrinogen levels and the bleeding and transfusion amount in pediatric cardiac surgery remains unclear. This study aimed to assess the association of pre-CPB fibrinogen levels (PreFib) and post-CPB fibrinogen levels (PostFib) with postoperative bleeding and transfusion volume in pediatric cardiac surgery.

Methods: We reviewed the medical records of 375 newborns and infants who underwent cardiac surgery under CPB for CHD. The primary endpoint was the correlation of the PreFib and PostFib values, as well as their difference (FibGap), with the bleeding and transfusion amount within 24 postoperative hours.

Results: There was no correlation of the PreFib, PostFib, and FibGap values with the bleeding and transfusion amounts at postoperative 24 hours. However, patients with PreFib and PostFib values of $<150$ and $<100 \mathrm{mg} / \mathrm{dL}$, respectively, showed a significantly higher frequency of postoperative platelet (PLT) transfusion. In patients with complex CHD, PreFib showed a weak negative correlation with the bleeding amount at postoperative 24 hours and the number of PLT-transfused patients.

Conclusions: Our findings suggest that in pediatric patients with CHD who cannot undergo point-ofcare (POC) tests, those presenting PreFib and PostFib values of $<150$ and $<100 \mathrm{mg} / \mathrm{dL}$, respectively, have a significantly higher frequency of postoperative PLT transfusion.

Keywords: Bleeding; blood transfusion; cardiac surgery; fibrinogen; pediatric

Submitted May 26, 2021. Accepted for publication Jul 13, 2021.

doi: $10.21037 / \mathrm{tp}-21-236$

View this article at: https://dx.doi.org/10.21037/tp-21-236

^ ORCID: Gyeong-Jo Byeon, 0000-0001-5333-3894; Hee Young Kim, 0000-0001-7809-8739. 


\section{Introduction}

Newborns and infants are at a high risk of massive bleeding after congenital heart surgery; moreover, postoperative bleeding increases the mortality rate after cardiopulmonary bypass (CPB) surgery. Additionally, increased pulmonary complications and delayed hospital stay may result from an increased blood transfusion volume $(1,2)$. Age and cyanotic disease are established risk factors for postoperative coagulopathy in pediatric cardiac surgery $(3,4)$. Other factors associated with increased bleeding after $\mathrm{CPB}$ include weight $(<8 \mathrm{~kg})$, complexity of surgery, duration of $\mathrm{CPB}$, length of deep hypothermic circulatory arrest (DHCA), and redo surgery $(3,5)$. In pediatric patients, specific factors, including the immature haemostatic system and a higher degree of bypass haemodilution, should be considered (6).

Fibrinogen is a plasma glycoprotein produced in the liver that is essential for blood coagulation; specifically, it mediates platelet (PLT) aggregation. Normal fibrinogen levels range from 150 to $400 \mathrm{mg} / \mathrm{dL}$ (7-9). Infants aged $<12$ months with congenital heart disease (CHD) present abnormal fibrinogen function (10) because there are differences in the biochemical composition and physical structure of the fibrinogen molecules between adults and infants (11), as well as blood dilution and wasting resulting from CPB during cardiac surgery $(12,13)$. According to von Felten's research, presence of fibrin degradation products (FDPs) has been with some cases of prolonged thrombin times (14). Pre- and postoperative plasma fibrinogen levels has been shown to affect the bleeding and transfusion amount in adult and pediatric patients undergoing cardiac surgery (15-19).

However, the research for identifying the relationship of plasma fibrinogen levels with the bleeding and transfusion amount in pediatric cardiac surgery remains lack. Additionally, the few related studies have had small sample sizes. This study aimed to investigate whether pre$\mathrm{CPB}$ fibrinogen levels (PreFib) and post-CPB fibrinogen levels (PostFib) were associated with postoperative bleeding and transfusion volume in pediatric cardiac surgery. We present the following article in accordance with the STROBE reporting checklist (available at https:// tp.amegroups.com/article/view/10.21037/tp-21-236/rc).

\section{Methods}

\section{Study design and patient population}

Between January 1, 2014, and September 30, 2016, medical records were reviewed for 375 newborns and infants who underwent $\mathrm{CPB}$ for $\mathrm{CHD}$, including simple (which may involve one heart valve or a hole inside the heart) and complex (which may affect several parts of the heart and how blood is circulated) heart anomalies. The study was conducted in accordance with the Declaration of Helsinki (as revised in 2013). The study was approved by the Institutional Review Board of Pusan National University Yangsan Hospital (Ref: 05-2016-160) and individual consent was waived due to the retrospective nature of the study.

\section{Clinical practice}

Anaesthesia was induced and maintained based on the pediatric cardiac anaesthesia protocol at Pusan National University Yangsan Hospital. The operation was performed under hypothermia (28-30 degrees); additionally, alphastat $\mathrm{pH}$ management and target perfusion pressure were maintained at $30-50 \mathrm{mmHg}$. Before CPB initiation, unfractionated heparin (300-400 unit $/ \mathrm{kg}$ ) was intravenously injected for anticoagulation. During the CPB maintenance period, heparin was added, as appropriate, to maintain an activated clotting time (ACT) for $>400$ seconds. Upon CPB weaning after completing the main procedure, heparin was reversed using protamine sulphate (1 mg/heparin 100 unit). Protamine sulfate $(0.5-1 \mathrm{mg} / \mathrm{kg})$ was additionally administered to maintain a baseline ACT of $<110 \%$. Fibrinogen levels were measured after anaesthesia induction (before skin incision) and protamine reversal. Transfusion during the perioperative period was performed following the standard transfusion guidelines in our hospital. In cases with clinically significant bleeding tendency and massive bleeding, additional blood coagulation factors and PLTs were added at the judgment of the operating physician and the anaesthesiologist.

Blood drained through the chest tube was postoperatively measured in the intensive care unit (ICU) for 24 postoperative hours and calculated as the bleeding amount. Further, the transfusion amount was defined as that within 24 postoperative hours in the ICU.

\section{Outcomes}

Normal fibrinogen levels range from 150-400 mg/dL (7-9); further, the reference pre-CPB value was set at $150 \mathrm{mg} / \mathrm{dL}$. The primary outcome was the correlation of the PreFib, PostFib, and fibrinogen gap (FibGap; PostFib - PreFib) values with blood loss and transfusion volume within 24 hours after pediatric cardiac surgery. Additionally, we 
investigated whether these factors affect the length of ICU stay and mechanical ventilation.

\section{Statistical analysis}

The normality of distribution was verified by Shapiro-Wilk normality test. Differences in PreFib, PostFib, FibGap, bleeding and transfusion amount, mechanical ventilation length, ICU stay, and dichotomous data were used to determined using Fisher's exact test. A two-sample $t$-test or the Wilcoxon rank-sum test was used for continuous data. Further, Pearson's correlation analyses were performed to determine the correlation between the bleeding and transfusion amount within 24 hours after pediatric cardiac surgery. Univariate logistic regression and receiver operating characteristic (ROC) analysis was also performed for verification of the association of PreFib level with other factors. Statistical significance was set at $\mathrm{P}$ value $<0.05$.

\section{Results}

\section{PreFib}

There was no significant between-group differences in age, height, weight, and CHD type based on a PreFib level of $150 \mathrm{mg} / \mathrm{dL}$. For patients with PreFib $<150 \mathrm{mg} / \mathrm{dL}$, preand post-operative fibrinogen levels were both lower; additionally, there were larger FibGap values than those in the group with $\geq 150 \mathrm{mg} / \mathrm{dL}$. Additionally, for patients with PreFib $<150 \mathrm{mg} / \mathrm{dL}$, there was no difference in the postoperative frequency of transfusion of packed red blood cells (pRBC) and fresh frozen plasma (FFP) in the ICU. However, there was a higher frequency of PLT transfusion. However, there was no between-group difference in the bleeding amount, length of ICU stay, and postoperative mechanical ventilation (Table 1).

\section{PostFib}

Upon group classification based on a PostFib value of $100 \mathrm{mg} / \mathrm{dL}$, there were no between-group difference in age and weight; however, there were between-group differences in height and CHD type. For patients with PostFib $\geq 100 \mathrm{mg} / \mathrm{dL}$, there was a large proportion of simple CHD. Additionally, for patients with PostFib $<100 \mathrm{mg} / \mathrm{dL}$, the CPB duration was $109 \min (31.00,278.00)$. Further, the duration of aortic cross clamping (ACC) was $76 \mathrm{~min}$ (13.00, 190.00), which was longer than that of the $\geq 100 \mathrm{mg} / \mathrm{dL}$ group. For patients with PostFib $<100 \mathrm{mg} / \mathrm{dL}$, both pre- and postoperative fibrinogen levels were both lower; additionally, the differences were smaller than those in the $\geq 100 \mathrm{mg} / \mathrm{dL}$ group. There was no between-group difference in the postoperative frequency of total transfusion (regardless of blood type) in the ICU. The frequencies of pRBC, FFP, and PLT transfusions in the ICU were higher in the PostFib $<100 \mathrm{mg} / \mathrm{dL}$ group; however, they showed low blood transfusion. There was no between-group difference in the postoperative bleeding amount, length of ICU stay, and postoperative mechanical ventilation (Table 2).

\section{FibGap}

Upon group categorization based on a FibGap value of $50 \mathrm{mg} / \mathrm{dL}$, there were no significant between-group differences in age, weight, and height; however, there were between-group differences in the CHD type. When the FibGap value was $<50 \mathrm{mg} / \mathrm{dL}$, there was a large proportion of simple CHD. Additionally, for patients with a FibGap value of $\geq 50 \mathrm{mg} / \mathrm{dL}$, the $\mathrm{CPB}$ duration was $110 \mathrm{~min}$ (31.00, $318.00)$ and the ACC duration was $73 \min (7.00,190.00)$, which was longer than that of patients with $<50 \mathrm{mg} / \mathrm{dL}$. In the FibGap $\geq 50 \mathrm{mg} / \mathrm{dL}$, both PreFib and PostFib values were higher than those in the $<50 \mathrm{mg} / \mathrm{dL}$ group. There was no between-group difference in the bleeding amount at 24 postoperative hours, the postoperative total frequency of transfusion in the ICU (regardless of the blood type, the frequency of pRBC, FFP, PLT, and pump blood transfusion. The length of ICU stay and mechanical ventilation was longer at FibGap $\geq 50 \mathrm{mg} / \mathrm{dL}[3.00$ days $(1.00,14.00)$ and 29.00 hours $(5.00,260.00)$, respectively] (Table 3).

\section{Comparison of characteristics between the simple and complex CHD groups}

Upon classification based on simple and complex CHD, there was no between-group difference in age, weight, height, and PreFib; however, there were significant between-group differences in PostFib and FibGap values. Moreover, there was a between-group difference in all the measured factors except the total number of transfused patients (Table 4). Therefore, we further analysed the correlation between PreFib levels and transfusion-related factors (Table 5). None of the factors showed a significant correlation; however, some factors showed a weakly negative correlation. Specifically, in complex CHD, there was a meaningful negative correlation of the bleeding amount at 
Table 1 Comparison of characteristics between high and low PreFib

\begin{tabular}{|c|c|c|c|c|}
\hline Variable & Overall $(n=375)$ & PreFib $<150 \mathrm{mg} / \mathrm{dL}(\mathrm{n}=106)$ & PreFib $\geq 150 \mathrm{mg} / \mathrm{dL}(\mathrm{n}=269)$ & $P$ value \\
\hline Complex CHD (\%) & $175(46.7)$ & $48(45.3)$ & $127(47.2)$ & \\
\hline Age (months) & $3.00[0.00,12.00]$ & $3.00[0.00,12.00]$ & $2.00[0.00,12.00]$ & 0.352 \\
\hline Weight (kg) & $5.59(1.98)$ & $5.59(1.83)$ & $5.59(2.04)$ & 0.990 \\
\hline \multicolumn{5}{|l|}{ Fibrinogen (mg/dL) } \\
\hline Pre-CPB & $171.00[76.80,415.00]$ & $131.25[76.80,149.00]$ & $191.00[150.00,415.00]$ & $0.000^{*}$ \\
\hline Post-CPB & $104.00[53.10,237.00]$ & $81.65[53.10,129.00]$ & $111.50[60.00,237.00]$ & $0.000^{*}$ \\
\hline Gap & $-67.00[-188.00,-17.90]$ & $-46.30[-83.90,-17.90]$ & $-77.00[-188.00,-27.00]$ & $0.000^{*}$ \\
\hline Post-CPB & $82.00[21.00,752.00]$ & $80.00[28.00,752.00]$ & $82.00[21.00,191.00]$ & 0.291 \\
\hline Gap & $-247.00[-552.00,383.00]$ & $-245.50[-511.00,383.00]$ & $-247.00[-552.00,-29.00]$ & 0.842 \\
\hline \multicolumn{5}{|l|}{$\mathrm{Hb}(\mathrm{g} / \mathrm{dL})$} \\
\hline Pre-CPB & $12.00[8.70,20.30]$ & $12.10[9.30,20.30]$ & $11.90[8.70,20.10]$ & 0.722 \\
\hline Post-CPB & $12.60[8.50,16.30]$ & $12.45[8.50,15.20]$ & $12.70[9.70,16.30]$ & 0.110 \\
\hline Gap & $0.40[-7.00,5.30]$ & $0.20[-5.70,5.30]$ & $0.50[-7.00,5.10]$ & 0.167 \\
\hline Duration of CPB (min) & $104.00[31.00,318.00]$ & $100.50[31.00,299.00]$ & $107.00[42.00,318.00]$ & 0.912 \\
\hline Duration of ACC (min) & $71.00[7.00,190.00]$ & $70.50[13.00,164.00]$ & $71.00[7.00,190.00]$ & 0.757 \\
\hline Total & $364(97.1)$ & $103(97.2)$ & $261(97.0)$ & 1.000 \\
\hline pRBC & $140(37.3)$ & $46(43.4)$ & $94(34.9)$ & 0.155 \\
\hline FFP & $47(12.5)$ & $16(15.1)$ & $31(11.5)$ & 0.387 \\
\hline PLT & $25(6.7)$ & $14(13.2)$ & $11(4.1)$ & $0.003^{*}$ \\
\hline Pump blood & $291(77.6)$ & $74(69.8)$ & $217(80.7)$ & $0.028^{*}$ \\
\hline Length of ICU stay (days) & $3.00[1.00,14.00]$ & $3.00[1.00,13.00]$ & $3.00[1.00,14.00]$ & 0.094 \\
\hline $\begin{array}{l}\text { Length of mechanical ventilation } \\
\text { (hours) }\end{array}$ & $27.00[5.00,260.00]$ & $25.00[6.00,260.00]$ & $28.00[5.00,220.00]$ & 0.077 \\
\hline
\end{tabular}

Two-sample $t$-test or Wilcoxon rank-sum test was performed for continuous data, and Fisher's exact test for categorical data. *, $\mathrm{P}$ value $<0.05$. PreFib, pre-CPB level of fibrinogen; CHD, congenital heart disease; CPB, cardiopulmonary bypass; PLT, platelet; Hb, hemoglobin; ACC, aortic cross clamping; pRBC, packed red blood cell; FFP, fresh frozen plasma; ICU, intensive care unit. 
Translational Pediatrics, Vol 11, No 4 April 2022

Table 2 Comparison of characteristics between high and low PostFib

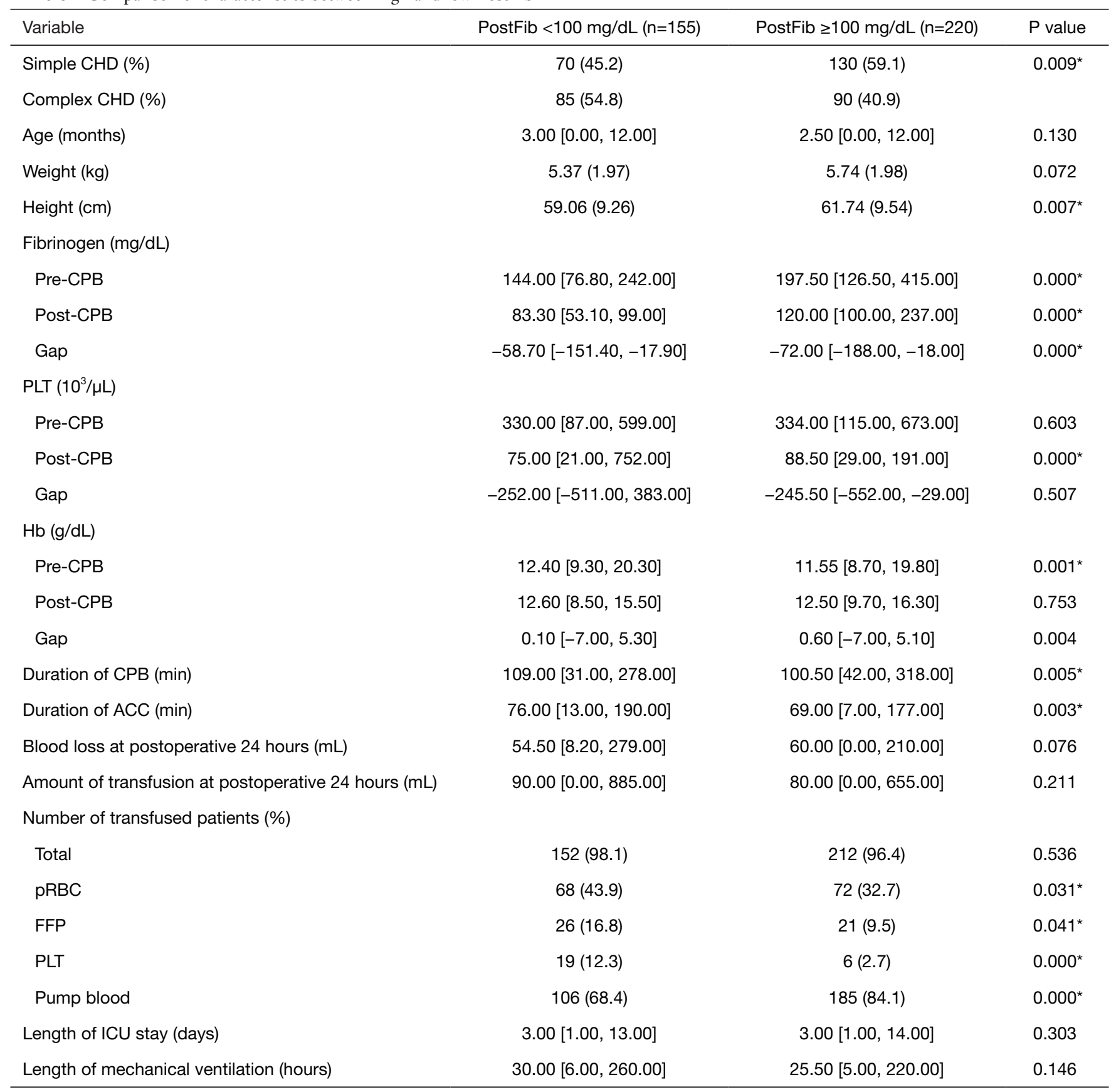

Two-sample $t$-test or Wilcoxon rank-sum test was performed for continuous data, and Fisher's exact test for categorical data. *, P value <0.05. PostFib, post-CPB level of fibrinogen; CHD, congenital heart disease; CPB, cardiopulmonary bypass; PLT, platelet; Hb, hemoglobin; ACC, aortic cross clamping; pRBC, packed red blood cell; FFP, fresh frozen plasma; ICU, intensive care unit. 
Table 3 Comparison of characteristics between high and low level of FibGap

\begin{tabular}{|c|c|c|c|}
\hline Variable & FibGap $<50$ mg/dL (n=91) & FibGap $\geq 50$ mg/dL $(n=284)$ & $P$ value \\
\hline Complex CHD (\%) & $30(33.0)$ & $145(51.1)$ & \\
\hline Age (months) & $3.00[0.00,12.00]$ & $2.00[0.00,12.00]$ & 0.052 \\
\hline Weight (kg) & $5.91(1.78)$ & $5.49(2.03)$ & 0.058 \\
\hline \multicolumn{4}{|l|}{ Fibrinogen (mg/dL) } \\
\hline Pre-CPB & $132.00[76.80,226.00]$ & $187.70[110.70,415.00]$ & $0.000^{\star}$ \\
\hline Post-CPB & $96.10[53.10,186.00]$ & $106.70[58.50,237.00]$ & $0.000^{\star}$ \\
\hline Gap & $-39.20[-49.90,-17.90]$ & $-75.00[-188.00,-50.00]$ & $0.000^{\star}$ \\
\hline Post-CPB & $85.00[32.00,752.00]$ & $79.00[21.00,191.00]$ & 0.095 \\
\hline Gap & $-237.00[-433.00,383.00]$ & $-248.00[-552.00,-29.00]$ & 0.246 \\
\hline \multicolumn{4}{|l|}{$\mathrm{Hb}(\mathrm{g} / \mathrm{dL})$} \\
\hline Pre-CPB & $11.50[9.30,20.30]$ & $12.25[8.70,20.10]$ & $0.002^{*}$ \\
\hline Post-CPB & $12.30[9.80,16.20]$ & $12.75[8.50,16.30]$ & $0.001^{*}$ \\
\hline Gap & $0.50[-5.50,5.30]$ & $0.40[-7.00,5.10]$ & 0.310 \\
\hline Duration of CPB (min) & $96.00[45.00,299.00]$ & $110.00[31.00,318.00]$ & $0.001^{*}$ \\
\hline Duration of ACC (min) & $66.00[19.00,140.00]$ & $73.00[7.00,190.00]$ & $0.009^{*}$ \\
\hline FFP & $9(9.9)$ & $38(13.4)$ & 0.468 \\
\hline PLT & $5(5.5)$ & $20(7.0)$ & 0.810 \\
\hline Pump blood & $72(79.1)$ & $219(77.1)$ & 0.773 \\
\hline Length of ICU stay (days) & $3.00[1.00,8.00]$ & $3.00[1.00,14.00]$ & $0.020^{\star}$ \\
\hline Length of mechanical ventilation (hours) & $24.00[6.00,187.00]$ & $29.00[5.00,260.00]$ & $0.005^{\star}$ \\
\hline
\end{tabular}

Two-sample $t$-test or Wilcoxon rank-sum test was performed for continuous data, and Fisher's exact test for categorical data. *, $\mathrm{P}$ value $<0.05$. FibGap, gap between pre- and post-CPB level of fibrinogen; CHD, congenital heart disease; CPB, cardiopulmonary bypass; PLT, platelet; Hb, hemoglobin; ACC, aortic cross clamping; pRBC, packed red blood cell; FFP, fresh frozen plasma; ICU, intensive care unit. 
Table 4 Comparison of characteristics between simple CHD group and complex CHD group

\begin{tabular}{|c|c|c|c|c|}
\hline Variable & Overall & Simple CHD & Complex CHD & $P$ value \\
\hline Age (months) & $3.00[0.00,12.00]$ & $2.00[0.00,12.00]$ & $3.00[0.00,12.00]$ & 0.333 \\
\hline Weight (kg) & $5.59(1.98)$ & $5.49(1.75)$ & $5.70(2.22)$ & 0.311 \\
\hline Height (cm) & $60.63(9.50)$ & $60.85(8.34)$ & $60.39(10.69)$ & 0.648 \\
\hline Pre-CPB & $171.00[76.80,415.00]$ & $166.30[100.60,356.00]$ & $180.00[76.80,415.00]$ & 0.129 \\
\hline Post-CPB & $104.00[53.10,237.00]$ & $106.00[59.80,210.90]$ & $100.80[53.10,237.00]$ & $0.001^{*}$ \\
\hline Gap & $-67.00[-188.00,-17.90]$ & $-60.00[-181.00,-18.00]$ & $-76.00[-188.00,-17.90]$ & $0.000^{*}$ \\
\hline \multicolumn{5}{|l|}{$\operatorname{PLT}\left(10^{3} / \mu \mathrm{L}\right)$} \\
\hline Gap & $-247.00[-552.00,383.00]$ & $-256.00[-552.00,-29.00]$ & $-234.00[-511.00,383.00]$ & $0.022^{*}$ \\
\hline \multicolumn{5}{|l|}{$\mathrm{Hb}(\mathrm{g} / \mathrm{dL})$} \\
\hline Pre-CPB & $12.00[8.70,20.30]$ & $11.20[8.80,20.10]$ & $13.20[8.70,20.30]$ & $0.000^{*}$ \\
\hline Post-CPB & $12.60[8.50,16.30]$ & $12.40[9.70,16.20]$ & $12.80[8.50,16.30]$ & $0.001^{*}$ \\
\hline Gap & $0.40[-7.00,5.30]$ & $0.95[-7.00,4.90]$ & $-0.60[-7.00,5.30]$ & $0.000^{*}$ \\
\hline Duration of CPB (min) & $104.00[31.00,318.00]$ & $88.00[42.00,187.00]$ & $138.00[31.00,318.00]$ & $0.000^{*}$ \\
\hline Duration of ACC (min) & $71.00[7.00,190.00]$ & $59.00[22.00,153.00]$ & $94.00[7.00,190.00]$ & $0.000^{*}$ \\
\hline $\begin{array}{l}\text { Blood loss at postoperative } \\
24 \text { hours (mL) }\end{array}$ & $50.70[8.20,279.00]$ & $41.90[8.20,154.10]$ & $69.00[14.80,279.00]$ & $0.000^{*}$ \\
\hline $\mathrm{pRBC}$ & $140(37.3)$ & $57(28.5)$ & $83(47.4)$ & $0.000^{*}$ \\
\hline FFP & $47(12.5)$ & $8(4.0)$ & $39(22.3)$ & $0.000^{*}$ \\
\hline PLT & $25(6.7)$ & $2(1.0)$ & $23(13.1)$ & $0.000^{*}$ \\
\hline Pump blood & $291(77.6)$ & $175(87.5)$ & $116(66.3)$ & $0.000^{*}$ \\
\hline Length of ICU stay (days) & $3.00[1.00,14.00]$ & $3.00[1.00,13.00]$ & $3.00[1.00,14.00]$ & $0.003^{*}$ \\
\hline $\begin{array}{l}\text { Length of mechanical ventilation } \\
\text { (hours) }\end{array}$ & $27.00[5.00,260.00]$ & $26.50[6.00,260.00]$ & $28.00[5.00,220.00]$ & $0.046^{*}$ \\
\hline
\end{tabular}

Two-sample $t$-test or Wilcoxon rank-sum test was performed for continuous data, and Fisher's exact test for categorical data. *, $\mathrm{P}$ value $<0.05$. CHD, congenital heart disease; CPB, cardiopulmonary bypass; PLT, platelet; Hb, hemoglobin; ACC, aortic cross clamping; pRBC, packed red blood cell; FFP, fresh frozen plasma; ICU, intensive care unit. 
Table 5 Correlation with level of fibrinogen pre-CPB and other factors

\begin{tabular}{|c|c|c|}
\hline Variable & Pearson $r$ & $P$ value \\
\hline Blood loss at postoperative 24 hours (mL) & -0.063 & 0.226 \\
\hline Amount of transfusion at postoperative 24 hours $(\mathrm{mL})$ & -0.053 & 0.309 \\
\hline \multicolumn{3}{|l|}{ Number of transfused patients (\%) } \\
\hline FFP & -0.013 & 0.800 \\
\hline PLT & -0.134 & $0.009^{*}$ \\
\hline Pump blood & 0.003 & 0.953 \\
\hline Length of ICU stay (days) & 0.163 & $0.002^{*}$ \\
\hline Blood loss at postoperative 24 hours (mL) & 0.012 & 0.866 \\
\hline Amount of transfusion at postoperative 24 hours $(\mathrm{mL})$ & 0.048 & 0.497 \\
\hline \multicolumn{3}{|l|}{ Number of transfused patients (\%) } \\
\hline pRBC & 0.105 & 0.138 \\
\hline FFP & 0.057 & 0.421 \\
\hline PLT & -0.085 & 0.232 \\
\hline Pump blood & -0.039 & 0.580 \\
\hline Length of ICU stay (days) & 0.133 & 0.061 \\
\hline $\mathrm{pRBC}$ & -0.122 & 0.109 \\
\hline FFP & -0.064 & 0.399 \\
\hline PLT & -0.195 & $0.010^{*}$ \\
\hline Pump blood & 0.062 & 0.415 \\
\hline Length of ICU stay (days) & 0.177 & $0.019^{*}$ \\
\hline Length of mechanical ventilation (hours) & 0.165 & $0.029^{*}$ \\
\hline
\end{tabular}

*, P value <0.05. CPB, cardiopulmonary bypass; $r$, correlation coefficient; pRBC, packed red blood cell; FFP, fresh frozen plasma; PLT, platelet; ICU, intensive care unit; CHD, congenital heart disease; 
Table 6 Univariate logistic regression and ROC analysis for the association of fibrinogen pre-CPB level with other factors

\begin{tabular}{lcc}
\hline Variable & Univariate analysis & ROC analysis \\
\hline Complex CHD $(\mathrm{n}=175)$ & OR $(95 \% \mathrm{Cl})$ & P value \\
Blood loss at postoperative 24 hours $(\mathrm{mL})$ & $0.994(0.987,1.000)$ & $0.044^{\star}$ \\
Amount of transfusion at postoperative 24 hours $(\mathrm{mL})$ & $0.999(0.994,1.005)$ & 0.842 \\
Number of transfused patients $(\%)$ & 0.606 \\
Total & $0.991(0.979,1.002)$ & 0.107 \\
pRBC & $0.997(0.991,1.003)$ & 0.310 \\
FFP & $0.995(0.988,1.003)$ & 0.221 \\
PLT & $0.991(0.982,1.001)$ & 0.075 \\
Pump blood & $1.005(0.999,1.011)$ & 0.548 \\
Length of ICU stay (days) & $1.002(0.995,1.008)$ & 0.127 \\
Length of mechanical ventilation (hours) & $1.002(0.996,1.008)$ & 0.632 \\
\hline
\end{tabular}

*, P value $<0.05$. ROC, receiver operating characteristic; CPB, cardiopulmonary bypass; CHD, congenital heart disease; OR, odds ratio; $\mathrm{Cl}$, confidence interval; $\mathrm{AUC}$, area under the curve; pRBC, packed red blood cell; FFP, fresh frozen plasma; PLT, platelet; ICU, intensive care unit.

24 postoperative hours with the number of PLT-transfused patients. However, univariate analysis, the only significant factor was the bleeding amount at 24 postoperative hours; moreover, the area under the curve of the total number of transfused patients was 0.717 (Table 6).

\section{Discussion}

This study revealed no correlation of the PreFib, PostFib, and FibGap values with the bleeding or transfusion amount at 24 postoperative hours. However, cases with PreFib $<150 \mathrm{mg} / \mathrm{dL}$ and PostFib $<100 \mathrm{mg} / \mathrm{dL}$ showed a significantly higher frequency of postoperative PLT transfusion. In patients with complex CHD, PreFib showed a weak negative correlation with the bleeding amount at postoperative 24 hours and the number of PLT-transfused patients. Univariate analysis revealed that the bleeding amount at postoperative 24 hours was significant; however, the odds ratio (OR) was 0.994 (0.987), which is indicative of a lack of a clinical significance.

In cardiac surgery under $\mathrm{CPB}$, coagulopathy can result from contact between blood and non-endothelial surfaces, anticoagulation using unfractionated heparin, protamine over dosage, and hypothermia, which causes massive bleeding (20). Coagulopathy in pediatric cardiac surgery under $\mathrm{CPB}$ may be more complex and associated with poor postoperative outcomes (1). Therefore, quick recognition of coagulopathy with appropriate haemostatic therapy in pediatric cardiac surgery could prevent postoperative bleeding, as well as reduce the morbidity, mortality, and costs.

Unfortunately, there remains no accurate biomarker for identifying individuals at a high-risk of post-CPB bleeding. Moreover, activated partial thromboplastin time, prothrombin time, and PLT count, which are commonly used in the perioperative period, have a low predictability for bleeding after cardiac surgery (21). Fibrinogen is a plasma protein crucially involved in haemostasis and clot formation. After cleavage through thrombin, it is polymerized to form fibrin strands, which create a structural network for effective clot formation (22). It has been reported that the pre- and postoperative plasma fibrinogen levels after adult cardiac surgery are independent predictors of the bleeding and transfusion amount (15). Blome and co-workers reported that in adult cardiac surgery, there is a negative relationship of the PreFib and PostFib with postoperative bleeding (23). Newborns and infants may present deficiencies in various coagulation factors in the plasmats (24), including fibrinogen dysfunction (25-27). Additionally, Faraoni and co-workers reported an association of low fibrinogen levels with severe postoperative bleeding in pediatric cardiac surgery. Moreover, the fibrinogen level naturally increases 
to the normal range after 24 postoperative hours (17). Taken together, fibrinogen supplementation may effectively prevent or treat postoperative bleeding in pediatric cardiac surgery. However, the optimal fibrinogen level for preventing bleeding and blood clots remain unclear.

Additionally, thromboelastography $\left(\mathrm{TEG}^{\circledR}\right.$, Haemostasis system, Haemoscope Corporation, Niles, IL, USA) or rotational thromboelastometry (ROTEM), which is a point-of-care (POC) test for bedside evaluation of all blood coagulation stages. TEM ${ }^{\circledR}$ International GmbH, Munich, Germany) has allowed algorithm-based transfusion and has been used in pediatric cardiac surgery (28-30). However, given that this equipment is not widely available across all medical institutions, we attempted to determine whether PreFib and PostFib levels could help determine postoperative bleeding and transfusion. Unfortunately, unlike previous findings on adult patients, our findings suggested that in pediatric cardiac surgery, the fibrinogen levels could not predict postoperative bleeding and transfusion.

To determine the functional ability of fibrinogen, thrombin and reptilase times are used for infants and children, respectively $(14,31)$, to measure the conversion rate of fibrinogen to fibrin after administering an external stimulant, including thrombin or reptilase (32). Test results can be prolonged by factors, including heparin, pathologic serum protein, and fibrinogen/FDPs (14). However, there remains controversy regarding whether the delay of test results is attributed to a fibrinogen conversion problem or a functional problem $(14,25)$. However, thrombin time has been reported to be further extended even in the absence of FDPs $(31,33)$. Taken together, these findings suggest that fibrinogen may present congenital functional abnormalities (dysfunctional 'foetal' fibrinogen) in infants. Although there was a between-group difference in fibrinogen levels, there was no between-group difference in the bleeding amount within 24 postoperative hours. This suggests that dysfunctional 'foetal' fibrinogen cannot be excluded since we included patients aged within 12 months. However, in complex CHD, PreFib revealed a weakly negative correlation with the bleeding amount at postoperative 24 hours and number of PLT-transfused patients. Additionally, in patients with PreFib and PostFib values of $<150$ and $<100 \mathrm{mg} / \mathrm{dL}$, respectively, the postoperative frequency of PLT transfusion was significantly higher; therefore, it can be clinically applied. For example, in cases where complex CHD surgery is required without POC tests, for patients with lower PreFib values than the normal range, blood supply may be prepared in advance to facilitate PLT transfusion.

This study has several limitations. First, pre- and post$\mathrm{CPB}$ transfusion may affect the postoperative bleeding and transfusion amount; however, we did not include this parameter. Second, regarding massive bleeding after weaning from $\mathrm{CPB}$, human fibrinogen, tranexamic acid, p-aminomethyl benzoic acid, and hemocoagulase were administered; however, these factors were not included. Third, POC tests, including the TEG and ROTEM, were not performed; moreover, we did not evaluate the actual fibrinogen-PLT interaction. Fourth, massive bleeding was defined by Martinowitz and Michaelson as the loss of entire blood volume within 24 hours (34); however, none of the patients met the criteria of the maximum bleeding amount. Therefore, we did not perform analysis divided into the bleeder and non-bleeder groups.

In conclusion, our findings indicated that pediatric patients (aged $<12$ months) with complex CHD undergoing cardiac surgery who show PreFib and PostFib $<150$ and $<100 \mathrm{mg} / \mathrm{dL}$, respectively, have a significantly higher frequency of postoperative PLT transfusion. Further research should be performed for identification of relationship between level of fibrinogen and transfusion.

\section{Acknowledgments}

The authors thank the Department of Biostatics, Clinical Trial Center, Biomedical Research Institute, Pusan National University Hospital for their contributions to this work.

Funding: None.

\section{Footnote}

Reporting Checklist: The authors have completed the STROBE reporting checklist. Available at https:// tp.amegroups.com/article/view/10.21037/tp-21-236/rc

Data Sharing Statement: Available at https://tp.amegroups. com/article/view/10.21037/tp-21-236/dss

Peer Review File: Available at https://tp.amegroups.com/ article/view/10.21037/tp-21-236/prf

Conflicts of Interest: All authors have completed the ICMJE uniform disclosure form (available at https://tp.amegroups. com/article/view/10.21037/tp-21-236/coif). The authors have no conflicts of interest to declare. 
Ethical Statement: The authors are accountable for all aspects of the work in ensuring that questions related to the accuracy or integrity of any part of the work are appropriately investigated and resolved. The study was conducted in accordance with the Declaration of Helsinki (as revised in 2013). The study was approved by the Institutional Review Board of Pusan National University Yangsan Hospital (Ref: 05-2016-160) and individual consent was waived due to the retrospective nature of the study.

Open Access Statement: This is an Open Access article distributed in accordance with the Creative Commons Attribution-NonCommercial-NoDerivs 4.0 International License (CC BY-NC-ND 4.0), which permits the noncommercial replication and distribution of the article with the strict proviso that no changes or edits are made and the original work is properly cited (including links to both the formal publication through the relevant DOI and the license). See: https://creativecommons.org/licenses/by-nc-nd/4.0/.

\section{References}

1. Guzzetta NA. Benefits and risks of red blood cell transfusion in pediatric patients undergoing cardiac surgery. Paediatr Anaesth 2011;21:504-11.

2. Murphy GJ, Reeves BC, Rogers CA, et al. Increased mortality, postoperative morbidity, and cost after red blood cell transfusion in patients having cardiac surgery. Circulation 2007;116:2544-52.

3. Miller BE, Mochizuki T, Levy JH, et al. Predicting and treating coagulopathies after cardiopulmonary bypass in children. Anesth Analg 1997;85:1196-202.

4. Eaton MP, Iannoli EM. Coagulation considerations for infants and children undergoing cardiopulmonary bypass. Paediatr Anaesth 2011;21:31-42.

5. Williams GD, Bratton SL, Ramamoorthy C. Factors associated with blood loss and blood product transfusions: a multivariate analysis in children after open-heart surgery. Anesth Analg 1999;89:57-64.

6. Osthaus WA, Boethig D, Johanning K, et al. Whole blood coagulation measured by modified thrombelastography (ROTEM) is impaired in infants with congenital heart diseases. Blood Coagul Fibrinolysis 2008;19:220-5.

7. Mosesson MW. Fibrinogen and fibrin structure and functions. J Thromb Haemost 2005;3:1894-904.

8. Standeven KF, Ariëns RA, Grant PJ. The molecular physiology and pathology of fibrin structure/function. Blood Rev 2005;19:275-88.
9. Kreuz W, Meili E, Peter-Salonen K, et al. Efficacy and tolerability of a pasteurised human fibrinogen concentrate in patients with congenital fibrinogen deficiency. Transfus Apher Sci 2005;32:247-53.

10. Miller BE, Tosone SR, Guzzetta NA, et al. Fibrinogen in children undergoing cardiac surgery: is it effective? Anesth Analg 2004;99:1341-6; table of contents.

11. Witt I, Müller H, Künzer W. Evidence for the existence of foetal fibrinogen. Thromb Diath Haemorrh 1969;22:101-9.

12. Kern FH, Morana NJ, Sears JJ, et al. Coagulation defects in neonates during cardiopulmonary bypass. Ann Thorac Surg 1992;54:541-6.

13. Chan AK, Leaker M, Burrows FA, et al. Coagulation and fibrinolytic profile of paediatric patients undergoing cardiopulmonary bypass. Thromb Haemost 1997;77:270-7.

14. von Felten A, Straub PW. Coagulation studies of cord blood, with special reference to "fetal fibrinogen". Thromb Diath Haemorrh 1969;22:273-80.

15. Pillai RC, Fraser JF, Ziegenfuss $M$, et al. Influence of circulating levels of fibrinogen and perioperative coagulation parameters on predicting postoperative blood loss in cardiac surgery: a prospective observational study. J Card Surg 2014;29:189-95.

16. Ucar HI, Oc M, Tok M, et al. Preoperative fibrinogen levels as a predictor of postoperative bleeding after open heart surgery. Heart Surg Forum 2007;10:E392-6.

17. Faraoni D, Willems A, Savan V, et al. Plasma fibrinogen concentration is correlated with postoperative blood loss in children undergoing cardiac surgery. A retrospective review. Eur J Anaesthesiol 2014;31:317-26.

18. Ozolina A, Strike E. Plasma fibrinogen level and postoperative bleeding after on-pump cardiac surgery. Acta Chir Hung 2011;11:79.

19. Jensen AS, Johansson PI, Bochsen L, et al. Fibrinogen function is impaired in whole blood from patients with cyanotic congenital heart disease. Int J Cardiol 2013;167:2210-4.

20. Paparella D, Brister SJ, Buchanan MR. Coagulation disorders of cardiopulmonary bypass: a review. Intensive Care Med 2004;30:1873-81.

21. Hall TS, Sines JC, Spotnitz AJ. Hemorrhage related reexploration following open heart surgery: the impact of pre-operative and post-operative coagulation testing. Cardiovasc Surg 2002;10:146-53.

22. Scheraga HA. The thrombin-fibrinogen interaction. Biophys Chem 2004;112:117-30.

23. Blome $M$, Isgro F, Kiessling AH, et al. Relationship 
between factor XIII activity, fibrinogen, haemostasis screening tests and postoperative bleeding in cardiopulmonary bypass surgery. Thromb Haemost 2005;93:1101-7.

24. Andrew M, Paes B, Johnston M. Development of the hemostatic system in the neonate and young infant. Am J Pediatr Hematol Oncol 1990;12:95-104.

25. Bleyer WA, Hakami N, Shepard TH. The development of hemostasis in the human fetus and newborn infant. J Pediatr 1971;79:838-53.

26. Gordon EM, Ratnoff OD, Saito H, et al. Studies on some coagulation factors (Hageman factor, plasma prekallikrein, and high molecular weight kininogen) in the normal newborn. Am J Pediatr Hematol Oncol 1980;2:213-6.

27. Andrew M, Bhogal M, Karpatkin M. Factors XI and XII and prekallikrein in sick and healthy premature infants. $\mathrm{N}$ Engl J Med 1981;305:1130-3.

28. Miller BE, Guzzetta NA, Tosone SR, et al. Rapid evaluation of coagulopathies after cardiopulmonary bypass in children using modified thromboelastography. Anesth Analg 2000;90:1324-30.

29. Theusinger OM, Felix C, Spahn DR. Strategies to reduce the use of blood products: a European perspective. Curr

Cite this article as: Byeon GJ, Yoon JU, Kim HJ, Choi EJ, Kim EJ, Park S, Park SJ, Heo W, Kim HY. The influence of circulating fibrinogen level on postoperative blood loss and blood transfusion in pediatric cardiac surgery: a retrospective observational study. Transl Pediatr 2022;11(4):514-1. doi: 10.21037/tp-21-236
Opin Anaesthesiol 2012;25:59-65.

30. Hayashi T, Sakurai Y, Fukuda K, et al. Correlations between global clotting function tests, duration of operation, and postoperative chest tube drainage in pediatric cardiac surgery. Paediatr Anaesth 2011;21:865-71.

31. Teger-Nilsson AC, Ekelund H. Fibrinogen to fibrin transformation in umbilical cord blood and purified neonatal fibrinogen. Thromb Res 1974;5:601-12.

32. Feldman MD, McCrae KR. Clinical coagulation laboratory evaluation of hemostasis in the perioperative period. In: Lake CL, Moore RA, editors. Blood: Hemostasis, Transfusion, and Alternatives in the Perioperative Period. New York: Raven Press, 1995:153-78.

33. Galanakis DK, Mosesson MW. Evaluation of the role of in vivo proteolysis (fibrinogenolysis) in prolonging the thrombin time of human umbilical cord fibrinogen. Blood 1976;48:109-18.

34. Martinowitz U, Michaelson M; Israeli Multidisciplinary rFVIIa Task Force. Guidelines for the use of recombinant activated factor VII (rFVIIa) in uncontrolled bleeding: a report by the Israeli Multidisciplinary rFVIIa Task Force. J Thromb Haemost 2005;3:640-8. 